\title{
Effectiveness of oral moxifloxacin in standard first-line therapy in community-acquired pneumonia
}

\author{
A. Torres*, J-F. Muir ${ }^{\#}$, P. Corris ${ }^{\uparrow}$, R. Kubin ${ }^{+}$, I. Duprat-Lomon ${ }^{\S}$, P-P. Sagnier ${ }^{f}$, G. Höffken**
}

Effectiveness of oral moxifloxacin in standard first-line therapy in community-acquired pneumonia. A. Torres, J-F. Muir, P. Corris, R. Kubin, I. Duprat-Lomon, P-P. Sagnier, G. Höffken. (C) ERS Journals Ltd 2003.

ABSTRACT: Based on recent guidelines for the management of community-acquired pneumonia, this study was designed to evaluate the effectiveness of a new fluoroquinolone compared with standard antimicrobial regimens, in conditions relating as closely as possible to the real world setting.

In this study, 564 patients were randomised to either oral moxifloxacin (400 mg o.d.) or to standard oral therapy (amoxicillin $1 \mathrm{~g}$ t.i.d. or clarithromycin $500 \mathrm{mg}$ b.i.d. alone or in combination) for up to $\mathbf{1 4}$ days using a double-blind procedure. The choice between the three standard regimens was made by the clinician prior to randomisation. Clinical response, quality of life, symptoms, healthcare resources and safety were assessed.

In the per-protocol population, clinical success was reported for 201 of $215(93.5 \%)$ and 217 of $231(93.9 \%)$ in the moxifloxacin and standard groups, respectively, at 7-10 days post-therapy. At 28-35 days follow-up, continued clinical cure was observed in 183 of $192(95.3 \%)$ moxifloxacin and 207 of $221(93.7 \%)$ standard groups. Drug-related adverse events were reported in 55 of $274(20 \%)$ moxifloxacin and 86 of $279(31 \%)$ standard patients with diarrhoea $>5 \%$.

Oral moxifloxacin monotherapy was as effective as, and better tolerated than, optimal antibiotic strategy represented either by mono- or combination therapy (amoxicillin and/or clarithromycin) in community-acquired pneumonia management. Eur Respir J 2003; 21: 135-143.
*Hospital Clinic of Barcelona, Villarroel, Barcelona, Spain. ${ }^{\#}$ CHU Rouen, Hôpital de Bois Guillaume, Rouen, France. Freeman Hospital, Newcastle, and ${ }^{f}$ Bayer Plc, Slough, UK. ${ }^{+}$Bayer AG, Wuppertal, and ${ }^{* *}$ Universitätsklinikum C G Carus, Dresden, Germany. ${ }^{\S}$ Bayer Pharma, Puteaux, France.

Correspondence: A. Torres, Clinical Institute of Pneumology and Thoracic Surgery, UVIR/Dept of Pulmonology, Hospital Clinic of Barcelona, Villarroel, 170, E-08036 Barcelona, Spain. Fax: 34932279813

E-mail: atorres@medicina.ub.es

Keywords: Community-acquired pneumonia, effectiveness, moxifloxacin, outcomes, safety

Received: May 292002

Accepted after revision: August 272002

This study was funded by Bayer AG, Wuppertal, Germany.
Community-acquired pneumonia (CAP) is a frequent cause of morbidity and mortality in Europe. Incidences range from $>800,000$ per year in Spain to $>1$ million per year in Italy. Incidence rates in Germany, France and the UK have also been reported between these estimates $[1,2]$. Overall, there are $>3$ million cases of CAP annually in Europe compared with an estimated 2-3 million seen in the USA each year [3]. In the USA, CAP is the sixth leading cause of death and the fifth cause in those $>65$ yrs of age, accounting for 290,000 deaths in $1997[4,5]$. Of these, up to $20 \%$ will be hospitalised [6], resulting in major financial impact [7]. Hospitalisation is the prime driver of CAP-associated costs, as shown by FINE and coworkers [8, 9], who developed criteria to predict either mortality or increased morbidity, the Pneumonia Severity Index (PSI) [8]. Clearly, both patients and the healthcare system would benefit if patients could be appropriately treated out of hospital or discharged earlier [9].

Several new approaches to the management of CAP have been published, including those of the Infectious Diseases Society of America [10], the Canadian Infectious Disease Society-Canadian Thoracic Society [11], the European Respiratory Society [12], the Drug-Resistant
Streptococcus pneumoniae Therapeutic Working Group [13] and the American Thoracic Society (ATS) [14].

In this context, the CAP 2000 study was developed to compare the main current antimicrobial treatments and their outcomes in CAP, in situations as closely related as possible to the general practice setting. The study compared a third-generation fluoroquinolone, moxifloxacin, given as a single first-line with a comparative arm, where the choice was given to investigators between a $\beta$-lactam, a macrolide or the combination of both. The selected products and their dosages were fixed and chosen according to guideline recommendations.

\section{Material and methods}

\section{Study design}

This phase IIIb study was designed to compare the effectiveness of moxifloxacin with standard recommended therapy. The choice of the standard regimen was made by the investigator prior to randomisation based on clinical presentation. Patients were then randomly allocated to either moxifloxacin $400 \mathrm{mg}$ o.d. 
orally or to one of three possible treatment options in the standard group, amoxicillin $1 \mathrm{~g}$ t.i.d., clarithromycin $500 \mathrm{mg}$ b.i.d., or the association of both regimens, according to a double-blind procedure, where both the patient and clinician did not know which treatment was administered. In both arms, patients received between 5-15 days of treatment.

Patients eligible for inclusion in the study were $\geqslant 18$ yrs of age with CAP clinically documented by the presence of fever, an elevated white blood cell count $\left(>100,000 \mu \mathrm{L}^{-1}\right)$, signs or symptoms of pneumonia and a new or progressive infiltrate on a chest radiograph. Patients were excluded for the following reasons: allergy to fluoroquinolones, pregnancy or lactating, hospitalisation for $>48 \mathrm{~h}$, rapid fatal underlying disease, history of fluoroquinolone tendinopathy, severe liver or renal impairment, administration of another investigational drug within 90 days of enrolment in the study, previous enrolment in this study, drugs treatment known to affect cardiac output interval and previous systemic use of antibiotics for $>24 \mathrm{~h}$ prior to enrolment. The study was approved by the institutional review board and all patients gave written, informed consent prior to enrolment.

Patients were examined at days 3-5 of treatment, days 7-10 (test of cure visit) and days 28-35 after the end of treatment. Clinical assessment included physical examination, blood pressure, cardiac frequency, respiration rate and mental state (on entry only). Temperature was recorded every $12 \mathrm{~h}$ for the first 5 days. Positive chest radiology was needed for inclusions, subsequent radiographs were at the discretion of the investigator. Similarly, bacteriological examinations were optional. Routine laboratory examinations of blood parameters were taken at the start of the study and followed in cases of abnormality or if deemed necessary by the investigator.

Symptoms were recorded with a specific 18-item questionnaire, the CAP-symptom, developed and validated within this study [15]. Quality of life was measured using a generic questionnaire the Acute MOS 36-Item Short-Form Health Survey (acute SF-36), at the beginning and end of the patient's inclusion in the study, with calculation of the SF-36 Physical Component Summary score (PCS), SF-36 Mental Component Summary score (MCS) and the eight SF-36 dimension scores [16]. In addition, the vitality subscale of the acute SF-36 was also used at days 3-5 and at test of cure. Healthcare resource utilisation, such as concomitant medications, diagnostic and therapeutic procedures, hospitalisation and visits to medical staff, were recorded. The parameters to calculate the PSI [8] for analysis were also collected at baseline. The consumption of main healthcare resources were described in the two treatment arms.

The clinical response at days 3-5, at test of cure and at days 28-35 after the end of the drug treatment was graded in three stages: 1) continued clinical cure (disappearance of acute signs and symptoms related to the infection maintained throughout the follow-up period); 2) clinical relapse (clinical cure at test of cure, with subsequent reappearance of signs and symptoms of CAP requiring antibacterial therapy within the 28-35 days after the drug treatment period); and 3) indeterminable (it was not possible to determine clinical assessment).

\section{Statistical analysis}

All patients who received at least one dose of moxifloxacin were evaluated for safety. The intentionto-treat (ITT) population included all the patients in the study who had received at least one dose of the study drug and whose essential data was complete (e.g. clinical evaluation at test of cure). The perprotocol (PP) population included patients matching the ITT criteria, who had a confirmed diagnosis of CAP and who had received study medication for a minimum of $48 \mathrm{~h}$ (in case of clinical failure) or 5 full days (in case of clinical cure).

Since the study aimed to compare moxifloxacin with standard treatment, reflecting the clinician's choice in the real world practice, it was powered as a two-arm comparison. The standard treatment arm offered three possible prerandomisation options but represented only a single arm for the purpose of randomisation and statistical analyses. The primary analysis was the clinical response at test of cure on the PP population. The two study groups were compared by using a one-sided $95 \%$ confidence interval (CI) for the difference in clinical success rates. If, and only if, the upper limit of this CI was $<10 \%$, moxifloxacin was proven to be at least as effective as the standard therapy.

The sample size was based on a conservative failure rate of $10 \%$ in the two arms, equivalence clinically relevant delta of $10 \%$, and power of $90 \%$. Taking into account a $15 \%$ increase in sample size to account for the multicentre design of the study, and assuming a validity rate of $80 \%, 269$ patients were enrolled in each group resulting in a total of 538 patients.

The secondary effectiveness variables were analysed on ITT population. These included the clinical response at days 3-5 (on treatment) and days 28-35 (after the end of the treatment), the CAP symptom score (derived from the validation statistical analysis) [15], the SF-36 scores (calculated according to the recommended algorithms) [17], and healthcare utilisation data reported in units consumed without direct economic valuation.

As well as the two-arm comparisons of clinical and nonclinical outcomes, regimen-specific clinical outcomes within standard treatment were also described.

\section{Results}

A total of 553 patients were randomised from 64 participating centres. A further 10 patients were invited to participate but declined before any drug was administered. Four-hundred and seventy-seven patients and 446 patients were included in the ITT and the PP analyses, respectively. The populations are depicted in figure 1. In total, 13 countries were involved in this study (table 1).

No between-group differences were found in the demographic characteristics, the medical history, the 


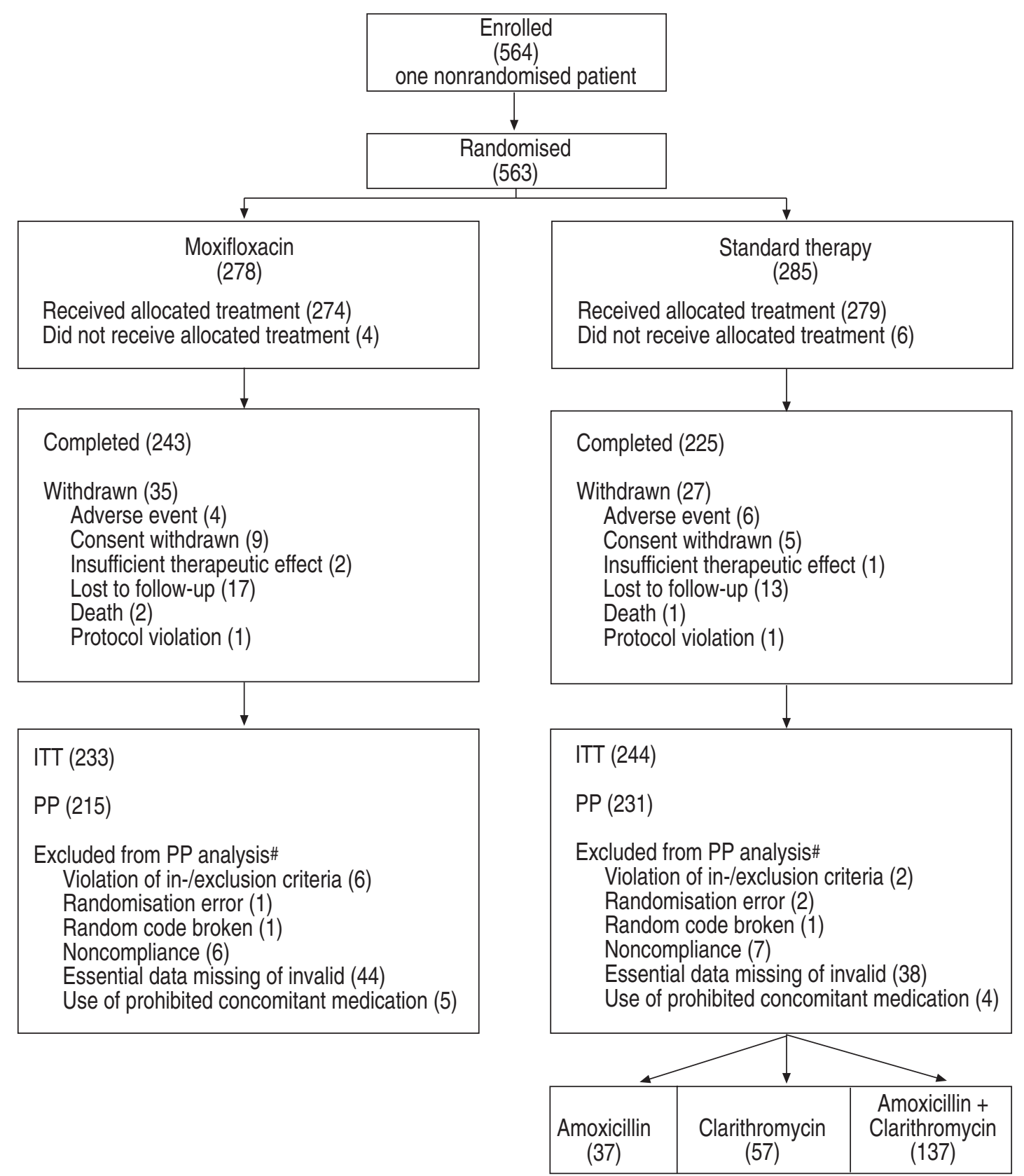

Fig. 1.-Study population. Number of patients in parentheses. ITT: intention-to-treat; PP: per-protocol. \#: patient may have more than one reason.

presenting signs and symptoms or the PSI (table 2). Globally, the PSI was distributed into class I (178 patients, $37 \%$ ), class II (108 patients, $23 \%$ ) and class III (109 patients, 23\%). Class IV and V, representing the most severe patients, comprised $75(16 \%)$ and seven patients, respectively.

Treatment compliance was similar in both groups, with 10 days as the mean length of study treatment duration. In the standard treatment arm, 143 of 244 patients received a combination of amoxicillin and clarithromycin. Monotherapy was received by 60 $(24 \%)$ and $41(17 \%)$ patients for clarithromycin and amoxicillin, respectively. Clinical presentation (88\%), radiological findings $(65 \%)$ and/or local susceptibility patterns $(26 \%)$ were described as the principal reasons for antibiotic choice.

In the PP population, clinical cure at test of cure was achieved by 201 of $215(93.5 \%)$ and 217 of 231 $(93.9 \%)$ of the moxifloxacin and standard group patients, respectively (table 3 ). This yielded a difference of $-0.4 \%(95 \% \mathrm{CI}-4.2-3.3 \%)$, demonstrating that moxifloxacin was as effective as the standard treatment. Follow-up at 28-35 days post-therapy showed a continued clinical cure of $95.3 \%$ (183 of 192) and $93.7 \%$ (207 of 221) for moxifloxacin and standard group patients, respectively (difference of $-1.5 \%, 95 \%$ CI $-2.2-5.2 \%$ ). In the ITT population the results shown earlier were confirmed at all assessment points 
Table 1. - Country details (intention-to-treat population)

\begin{tabular}{|c|c|c|c|c|c|}
\hline \multirow[t]{2}{*}{ Country } & \multirow[t]{2}{*}{ Moxifloxacin } & \multicolumn{3}{|c|}{ Standard treatment } & \multirow[t]{2}{*}{ Total } \\
\hline & & Amoxicillin & Clarithromycin & Amoxicillin+clarithromycin & \\
\hline France & 18 & 8 & 3 & 13 & 42 \\
\hline Germany & 24 & 7 & 8 & 9 & 48 \\
\hline Hungary & 31 & 2 & 9 & 23 & 65 \\
\hline Israel & 24 & 1 & 6 & 18 & 49 \\
\hline Italy & 8 & 0 & 0 & 8 & 16 \\
\hline Norway & 5 & 4 & 0 & 1 & 10 \\
\hline Poland & 25 & 0 & 8 & 20 & 53 \\
\hline Portugal & 2 & 0 & 0 & 4 & 6 \\
\hline S. Africa & 31 & 4 & 2 & 27 & 64 \\
\hline Spain & 25 & 3 & 13 & 5 & 46 \\
\hline Sweden & 16 & 8 & 5 & 3 & 32 \\
\hline Switzerland & 4 & 0 & 1 & 3 & 8 \\
\hline UK & 20 & 4 & 5 & 9 & 38 \\
\hline Subtotal & & $41(17 \%)$ & $60(24 \%)$ & $143(59 \%)$ & \\
\hline Total & 233 & $244(100 \%)$ & & & 477 \\
\hline
\end{tabular}

(table 3). The rate of clinical cure was similar between the different regimens within the standard therapy arm, both in monotherapy (amoxicillin or clarithromycin), $94.1 \%$ (95 of 101) at test of cure and 91.8\% (89 of 97) at 28-35 days follow-up, and in combination (amoxicillin+clarithromycin), 93.7\% (134 of 143) at test of cure and $94.2 \%$ (129 of 137) at 28-35 days follow-up, respectively. Descriptive results were also expressed according to the PSI classification at study entry. These levels of clinical success rate were mainly consistent across the classes of PSI and within the

Table 2.-Patient demographics and medical history (intention-to-treat population)

\begin{tabular}{lcc}
\hline Patients & Moxifloxacin & $\begin{array}{c}\text { Standard } \\
\text { treatment }\end{array}$ \\
\hline Demographics & & \\
Age yrs & $52.7 \pm 18.7$ & $49.3 \pm 18.7$ \\
Age $<50$ yrs & $97(42)$ & $126(52)$ \\
Age $\geqslant 70$ yrs & $52(22)$ & $44(18)$ \\
Sex male & $137(59)$ & $133(55)$ \\
Medical history & & \\
Previous or present smoker & $130(55.8)$ & $128(52.5)$ \\
No disease & $60(25.8)$ & $71(29.1)$ \\
Baseline characteristics & & \\
Temperature ${ }^{\circ}$ C & $38.4 \pm 0.8$ & $38.5 \pm 0.8$ \\
Respiration rate breath·min ${ }^{-1}$ & $21.8 \pm 7.3$ & $21.9 \pm 5.8$ \\
Previous antimicrobials & $48(20.6)$ & $58(23.8)$ \\
Chest radiographs & & \\
$\quad$ Bilateral infiltrate & $36(15.5)$ & $32(13.1)$ \\
$\quad$ Multilobar & $39(16.7)$ & $35(14.3)$ \\
$\quad$ Pleural effusion & $30(12.9)$ & $19(7.8)$ \\
PSI class & & \\
I & $80(34.3)$ & $98(40.2)$ \\
II & $52(22.3)$ & $56(23.0)$ \\
III & $56(24.0)$ & $53(21.7)$ \\
IV & $41(17.6)$ & $34(13.9)$ \\
V & $4(1.7)$ & $3(1.2)$ \\
Hospitalisation & & \\
Hospitalised pre-therapy & $12(5)$ & $13(5)$ \\
\hline
\end{tabular}

Data are presented as mean \pm SD or n (\%). PSI: pneumonia severity index. different dosage regimen in the standard group (table 4).

At baseline, $55-58 \%$ of enrolled patients had a temperature $>38.5^{\circ} \mathrm{C}$ and no difference was found in the subsequent development of a temperature between the two groups. Likewise, the median of symptom scores regularly improved during the study period with no statistically significant differences between the groups (table 5). The SF-36 questionnaire was completed by $96 \%$ of patients. The eight dimension scores as well as the PCS and MCS increased consistently at the end of the study period in comparison with at study entry, with no differences between treatment groups, indicating improvement in patient health status (table 6).

Likewise, concomitant medications, post-therapy antimicrobial treatments, hospitalisation patterns and requirements for additional therapeutic procedures were distributed similarly between the two groups (table 7).

A total of 553 patients were included in the safety analysis. The incidence of adverse events was similar between moxifloxacin and standard treatment (48 and $54 \%$, respectively; table 8 ). The incidence of reported adverse events possibly related to the therapy was statistically lower with moxifloxacin than in the standard arm (20 versus $31 \%$ respectively, $\mathrm{p}=0.004$ ). Possible drug-related adverse events are summarised in table 8 . Diarrhoea, the most common adverse event, was reported in $22(8 \%)$ and $13(5 \%)$ patients with standard treatment and moxifloxacin, respectively. Adverse events were reported more frequently among amoxicillin patients (37 of $53(69.8 \%)$ ) than with the two other dosage regimens, i.e. clarithromycin alone (38 of $71(53.5 \%)$ ) and in combination with amoxicillin (75 of $155(48.4 \%)$ ). This trend in adverse events was confirmed as probably drug-related: amoxicillin (22 of $51(41.5 \%)$ ), clarithromycin (20 of $71(28.2 \%)$ ) and bitherapy (44 of $155(28.4 \%))$. Diarrhoea and nausea were the most common reported events with amoxicillin, in eight (15.1\%) and two $(3.8 \%)$ patients, respectively. This was also 
Table 3.-Clinical success rates at test of cure (TOC) and follow-up (per-protocol (PP) and intention-to-treat (ITT) populations)

\begin{tabular}{|c|c|c|c|c|}
\hline \multirow[t]{2}{*}{ Clinical success } & \multicolumn{2}{|c|}{$\mathrm{TOC}^{\#}$} & \multicolumn{2}{|c|}{ Follow-up } \\
\hline & Moxifloxacin & Standard treatment & Moxifloxacin & Standard treatment \\
\hline \multicolumn{5}{|l|}{ PP population } \\
\hline $\begin{array}{l}\text { Success } \\
95 \% \text { CI }\end{array}$ & $\begin{array}{c}201 / 215(93.5 \%) \\
-4.2-3.3\end{array}$ & $217 / 231(93.9 \%)$ & $\begin{array}{c}183 / 192(95.3 \%) \\
-2.2-5.2\end{array}$ & 207/221 (93.7\%) \\
\hline \multicolumn{5}{|l|}{ ITT population } \\
\hline $\begin{array}{l}\text { Success } \\
95 \% \text { CI }\end{array}$ & $\begin{array}{c}218 / 233(93.6 \%) \\
-3.9-3.3\end{array}$ & $229 / 244(93.9 \%)$ & $\begin{array}{c}196 / 208(94.2 \%) \\
-2.9-4.8\end{array}$ & $218 / 234(93.2 \%)$ \\
\hline
\end{tabular}

CI: confidence interval. ${ }^{\#}$ : 7-10 days post-therapy; ${ }^{\bullet}$ : 28-35 days post-therapy.

Table 4. - Descriptive clinical success rates at test of cure (TOC) and follow-up according to the pneumonia severity index (PSI) (intention-to-treat population)

\begin{tabular}{|c|c|c|c|c|}
\hline \multirow{2}{*}{$\begin{array}{l}\text { PSI } \\
\text { class }\end{array}$} & \multirow[t]{2}{*}{ Moxifloxacin } & \multicolumn{3}{|c|}{ Standard treatment } \\
\hline & & $\begin{array}{l}\text { SRT (monotherapy } \\
\text { or combination) }\end{array}$ & $\begin{array}{l}\text { Monotherapy (amoxicillin } \\
\text { or clarithromycin) }\end{array}$ & $\begin{array}{l}\text { Combination (amoxicillin+ } \\
\text { clarythromicin) }\end{array}$ \\
\hline$I^{\#}$ & 77/80 (96.3) & 95/98 (96.9) & 45/47 (95.7) & 50/51 (98.0) \\
\hline $\mathrm{II}^{\#}$ & $50 / 52(96.2)$ & $54 / 56(96.4)$ & $20 / 20(100)$ & $34 / 36(94.4)$ \\
\hline IIII $^{\#}$ & $50 / 56(89.3)$ & $49 / 53(92.5)$ & $17 / 19(89.5)$ & $32 / 34(94.1)$ \\
\hline $\mathrm{IV}^{\#}$ & $38 / 41(92.7)$ & $28 / 34(82.4)$ & $12 / 14(85.7)$ & $16 / 20(80.0)$ \\
\hline $\mathrm{V}^{\#}$ & $3 / 4(75.0)$ & $3 / 3(100.0)$ & $1 / 1(100.0)$ & $2 / 2(100.0)$ \\
\hline $\mathrm{I}^{\bullet}$ & $71 / 75(94.7)$ & $91 / 94(96.7)$ & $42 / 45(93.3)$ & 49/49 (100.0) \\
\hline III $^{\oplus}$ & $46 / 47$ (97.9) & $51 / 55(92.7)$ & $20 / 20(100.0)$ & $31 / 35(88.6)$ \\
\hline III $^{\bullet}$ & $49 / 53(92.5)$ & $45 / 49$ (91.8) & $45 / 49(91.8)$ & $15 / 18(83.3)$ \\
\hline $\mathrm{IV}^{\oplus}$ & $27 / 30(90.0)$ & $28 / 33(84.8)$ & $28 / 33(84.8)$ & $11 / 13(84.6)$ \\
\hline$V^{\oplus}$ & $3 / 3(100.0)$ & $3 / 3(100.0)$ & $1 / 1(100.0)$ & $2 / 2(100.0)$ \\
\hline
\end{tabular}

Data are presented as n (\%). SRT: standard regimen therapy. ${ }^{\#}$ : clinical cure at TOC (7-10 days post-therapy); ${ }^{\circ}$ : clinical cure at follow-up (28-35 days post-therapy).

the case for the combination of amoxicillin and clarithromycin: diarrhoea in $11(7.1 \%)$ and nausea in two $(1.3 \%)$ patients; the incidence rate in clarithromycin-treated patients was $4.2 \%$ (three patients) and $1.4 \%$ (one patient), respectively.

Overall, nine deaths were reported during the study, four in the moxifloxacin group (severe chronic obstructive pulmonary disease and suspected Clostridium

Table 5. - Community-acquired pneumonia symptom questionnaire: completion and scores (intention-to-treat population)

\begin{tabular}{|c|c|c|}
\hline & Moxifloxacin & Standard treatment \\
\hline Subjects n & 233 & 244 \\
\hline \multicolumn{3}{|l|}{ Pre-therapy } \\
\hline Completion & $230(99)$ & 242 (99) \\
\hline Score & $34.3 \pm 13.2$ & $33.9 \pm 13.6$ \\
\hline \multicolumn{3}{|l|}{ During therapy } \\
\hline Completion & 231 (99) & $238(98)$ \\
\hline Score & $20.9 \pm 11.8$ & $20.6 \pm 11.0$ \\
\hline \multicolumn{3}{|l|}{ Test of cure } \\
\hline Completion & $220(94)$ & 229 (94) \\
\hline Score & $13.5 \pm 11.5$ & $12.0 \pm 10.3$ \\
\hline \multicolumn{3}{|l|}{ Follow-up } \\
\hline Completion & $216(93)$ & $232(95)$ \\
\hline Score & $10.1 \pm 10.9$ & $9.6 \pm 10.8$ \\
\hline
\end{tabular}

Data are presented as mean \pm SD or $\mathrm{n}(\%)$ unless otherwise stated. difficile diarrhoea, pneumonia, sarcoidosis, heart failure) and five in the standard group (bronchial occlusion, multiorgan failure, cardiac and respiratory arrest, atypical pneumonia and lung cancer). Serious or life-threatening events were noted in $24(9 \%)$ and 33 $(12 \%)$ patients in the moxifloxacin and standard groups, respectively. Notably, none of the deaths or serious/life-threatening adverse events were attributed to or suggestive of arrhythmia or cardiac arrest. Overall, there were no significant differences in physical findings such as blood pressure or heart or respiration rates between treatment groups.

\section{Discussion}

In this study, $400 \mathrm{mg}$ moxifloxacin orally o.d. proved to be as an effective first-line therapy as the standard mono- or combination therapy chosen on a per-patient basis by investigators. The present results suggest, according to recent ATS guidelines [14], that quinolones for nonhospitalised and hospitalised CAP patients may be given at the same level of efficacy as $\beta$-lactams and macrolides. Moxifloxacin was significantly better tolerated than standard treatment with fewer drug-related adverse events.

This innovative outcomes study has several strengths that distinguish it from prior studies in CAP. Typically, phase III clinical trials are designed 
Table 6. - Short-form 36: completion and domain scores (intention-to-treat population)

\begin{tabular}{|c|c|c|c|c|}
\hline & \multicolumn{2}{|c|}{ Moxifloxacin } & \multicolumn{2}{|c|}{ Standard treatment } \\
\hline & Pre-therapy & Follow-up & Pre-therapy & Follow-up \\
\hline Subjects $\mathrm{n}$ & \multicolumn{2}{|c|}{233} & \multicolumn{2}{|c|}{244} \\
\hline Completion rate $\mathrm{n}(\%)$ & $224(96)$ & $210(96)$ & $239(98)$ & $230(97)$ \\
\hline Physical functioning & $46.2 \pm 28.9$ & $82.4 \pm 24.3$ & $44.9 \pm 28.2$ & $81.9 \pm 25.4$ \\
\hline Bodily pain & $47.2 \pm 30.4$ & $88.6 \pm 20.7$ & $45.8 \pm 29.9$ & $85.5 \pm 23.3$ \\
\hline General health perception & $57.9 \pm 26.8$ & $67.9 \pm 23.5$ & $47.2 \pm 30.4$ & $68.7 \pm 23.1$ \\
\hline Social functioning & $53.1 \pm 31.7$ & $88.8 \pm 20.0$ & $49.6 \pm 29.7$ & $85.6 \pm 23.8$ \\
\hline Role limitations due to physical health problems & $19.0 \pm 32.9$ & $82.8 \pm 32.5$ & $22.6 \pm 37.1$ & $78.5 \pm 36.8$ \\
\hline Role limitations due to emotional problems & $57.4 \pm 45.3$ & $89.5 \pm 25.6$ & $50.3 \pm 45.9$ & $85.2 \pm 32.3$ \\
\hline Mental health & $58.1 \pm 25.0$ & $81.3 \pm 19.0$ & $57.2 \pm 23.6$ & $81.2 \pm 17.7$ \\
\hline Vitality/energy & $33.5 \pm 23.8$ & $71.6 \pm 24.0$ & $32.4 \pm 24.0$ & $71.6 \pm 23.2$ \\
\hline PCS & $34.0 \pm 9.8$ & $49.9 \pm 9.4$ & $34.5 \pm 9.3$ & $49.3 \pm 9.8$ \\
\hline MCS & $43.0 \pm 12.9$ & $54.3 \pm 8.6$ & $41.3 \pm 12.5$ & $53.6 \pm 9.4$ \\
\hline
\end{tabular}

Data are presented as mean $\_$SD unless otherwise stated. PCS: Physical Component Summary; MCS: Mental Component Summary.

Table 7. - Consumption of healthcare resources (intentionto-treat population)

\begin{tabular}{|c|c|c|}
\hline & Moxifloxacin & $\begin{array}{l}\text { Standard } \\
\text { treatment }\end{array}$ \\
\hline Subjects n & 233 & 244 \\
\hline \multicolumn{3}{|l|}{ Medication } \\
\hline Any concomitant & $105(45)$ & $114(47)$ \\
\hline Post-therapy antimicrobials & $34(15)$ & $29(12)$ \\
\hline Post-therapy anti-infectives & $32(14)$ & $27(11)$ \\
\hline \multicolumn{3}{|l|}{$\begin{array}{l}\text { Number of chest radiographs } \\
\text { (excluding visit } 1 \text { ) }\end{array}$} \\
\hline 0 & $73(31)$ & $80(33)$ \\
\hline 1 & $83(36)$ & $87(36)$ \\
\hline$\geqslant 2$ & 77 (33) & $77(32)$ \\
\hline \multicolumn{3}{|l|}{ Hospitalisation status } \\
\hline Hospitalised during the study & $141(61)$ & $153(63)$ \\
\hline $\begin{array}{l}\text { Still hospitalised at the end } \\
\text { of the study }\end{array}$ & $4(2)$ & $5(2)$ \\
\hline $\begin{array}{l}\text { Length of stay days: median } \\
\text { (minimum-maximum) }\end{array}$ & $7.0(2-49)$ & $7.0(2-30)$ \\
\hline \multicolumn{3}{|l|}{ Type of ward } \\
\hline General medicine & $100(43)$ & $114(47)$ \\
\hline ICU & $1(0.4)$ & $3(1)$ \\
\hline Infectious disease & $9(4)$ & $7(3)$ \\
\hline Respiratory & $31(13)$ & $32(13)$ \\
\hline \multicolumn{3}{|l|}{ Work status } \\
\hline $\begin{array}{l}\text { Patients who returned to } \\
\text { work }\end{array}$ & $85(37)$ & $102(42)$ \\
\hline $\begin{array}{l}\text { Patients who did not } \\
\text { return to work }\end{array}$ & $12(5)$ & $20(8)$ \\
\hline $\begin{array}{l}\text { Requirements to any other } \\
\text { medical staff }\end{array}$ & $35(15)$ & $37(15)$ \\
\hline
\end{tabular}

Data are presented as n (\%) unless otherwise stated. ICU: intensive care unit.

to achieve regulatory approval. The protocol-driven experimental setting maximises the internal validity of the test of a primary research hypothesis, but in doing so, the extrapolation of study results to conditions of real use is limited. With the rising importance of evidence-based medicine, this trade-off has been recognised and various methodological solutions proposed $[18,19]$. They range from statistical modelling
Table 8. - Safety evaluation: incidence of adverse events (AE) (safety population)

\begin{tabular}{lcc}
\hline & Moxifloxacin & $\begin{array}{c}\text { Standard } \\
\text { treatment }\end{array}$ \\
\hline Subjects n & 274 & 279 \\
Overall incidence of any AE & $132(48)$ & $150(54)$ \\
AE possibly related to therapy & $55(20)$ & $86(31)^{\#}$ \\
$\quad$ Diarrhoea & $13(4.7)$ & $22(7.9)$ \\
Nausea & $10(3.6)$ & $5(1.8)$ \\
Dizziness & $1(0.4)$ & $3(1.1)$ \\
Headache & $5(1.8)$ & $4(1.4)$ \\
Taste perversion & $1(0.4)$ & $6(2.2)$ \\
Serious or life-threatening AE & $24(9)$ & $33(12)$ \\
Premature termination due to AE & $25(9)$ & $23(8)$ \\
Deaths & 4 & 5 \\
\hline
\end{tabular}

Data are presented as n (\%). ${ }^{\#}$ : $\mathrm{p}=0.004$.

of efficacy trial results, using epidemiological and economic data from the real world [20-22], to the design of pragmatic trials where protocol-driven constraints are relaxed and statistical analysis schemes modified in order to facilitate decision making rather than hypothesis testing $[23,24]$. The present study was designed to maintain a high degree of internal validity while maximising the generalisation of results. The internal validity of the study was ensured by a randomised, double-blinded, controlled study complying with good clinical practices. The external validity was enhanced by the fact that the choice of the comparator was left to the discretion of the investigator prior to randomisation. This feature allowed the optimisation of the choice of treatment based on the patient's presentation. The predefined choice of alternative antibiotics was carefully selected to represent current guidelines. Inclusion/exclusion criteria were left as broad as possible, so that the study population remained as similar as possible to CAP patients in the real world. Likewise, protocol-driven requests were limited as much as possible (no requested bacteriological, radiological follow-up). Finally, patientreported outcomes measures have been included in the 
study. This was meant to reinforce the generalisation of study results from both a healthcare effectiveness and a patient's perspective [25-27].

Recent guidelines for management of CAP in adults were reflected by the choice of antibiotics selected in this study [10-14]. Both monotherapy, a new macrolide or a $\beta$-lactam (usually an aminopenicillin at a high dose) or combination of these drugs are recommended as first-line in nonhospitalised and hospitalised CAP patients. New fluoroquinolones in monotherapy, such as moxifloxacin, gatifloxacin or levofloxacin, have been suggested as first-line antibiotics in CAP. Several studies have compared new fluoroquinolones with amoxicillin [28-31] or with second- and thirdgeneration cephalosporin [32-35] or macrolide, such as clarithromycin [36-41]. However, no single study has embraced all of the therapeutically recognised options in CAP in an effectiveness analysis like that conducted in the present investigation. The present study was not designed to show equivalence with a single monotherapy regimen, although descriptive analyses per-product are consistent with previously published studies. Clinical success rates with moxifloxacin in CAP have ranged $90-94 \%$ in phase III studies against clarithromycin [36] and high-dose amoxicillin [28]. The clinical cure rate of $93 \%$ with moxifloxacin was in keeping with previous studies; however, this study involved a range of illness severities comprising PSI I-V cases representing all severity stages of the disease. Again, according to recent ATS guidelines [14], this finding suggests that new quinolones in monotherapy are at the same level of efficacy as $\beta$-lactams alone or in combination with macrolides for treatment of hospitalised and nonhospitalised CAP.

A strength of the present study was also its demonstration of equivalence to a potentially much stronger comparator arm, i.e. the free choice by clinician between two monotherapy and one combination therapy options. In fact, when asked about treatment choice in the present study, investigators in a vast majority ( $88 \%$ of patients were concerned) indicated that the clinical presentation of the patients was the major factor of the treatment decision. This attitude is consistent with the view of most clinicians, which takes into account the clinical status and the probable bacteriological diagnosis in the initiation of the proper therapeutic class choice for first-line treatment.

This innovative study design also provided some insight into the impact of CAP on quality of life and specific symptoms. The combined approach, using both a generic and a disease-specific instrument, was complementary in the evaluation of disease treatment and provided useful findings for any further research in CAP care assessment [15].

Moxifloxacin treatment was significantly better tolerated than standard regimens with fewer adverse events and premature discontinuations. The drugrelated events seen in this study are usual in antimicrobial treatments, with a predominance of mild gastrointestinal upsets. The rate of these events compares favourably with previous clinical trial experiences seen with both regimens. Recent data on moxifloxacin showed nausea $(8 \%)$ and diarrhoea $(6 \%)$ as being the most frequent events [42, 43].

The mortality rate seen in this study was low (nine of 553). Indeed, most of the deaths were not attributable to studied treatment. There were insufficient cases in the more severe groups (PSI class V), where mortality rates are generally higher, to draw any conclusions. Thus, the safety profiles of the two treatment groups were generally unremarkable and revealed only typical adverse events associated with antimicrobials, such as diarrhoea and nausea. Overall, however, moxifloxacin-treated patients had a significantly lower incidence of adverse events.

To conclude, this innovative outcomes study supports the use of moxifloxacin as a first-line option for CAP. This treatment was as effective as an alternative of mono- or combination therapy, selected by a physician as the optimal treatment on a patient basis, and representing the maximal therapy option from main current guidelines. The safety profile of moxifloxacin was also favourable, with fewer drug-related adverse events in comparison to alternative standard treatment options.

These results of the Community-Acquired Pneumonia 2000 study may be the basis for future studies that could be in agreement with American Thoracic Society recommendations, advising the use of the most potent antipneumococcal antibiotics when the suspicion of resistances to Streptococcus pneumoniae is high, which may translate into differences in resistance rates and clinical success in the future.

Acknowledgements. The authors would like to gratefully acknowledge L.A. Mandell for advising on the study design and providing input to the manuscript. The authors would also like to thank all the study investigators in each of the following clinical sites. France: D. Benhamou, J-F. Muir, P. Petitpretz, R. Azarian, L. Bernabeu, P. Dumont, B. Castan, J. Vanche, L. de Saint Martin Pernot, J. Clavier, D. Yatim, D. Baron, A. Le Groumellec; Germany: K. Colberg, H. Common, R. Dichmann, C. Klein, J. Minnich, O. Gobrecht, G. Krause, K. Fehring, U. Harnest, R. Kraas, L. Leonhardt, S. Molitor, K. Kurz, W. Kreisel; Hungary: M. Szilasi, N. Dudas, I. Edes, A. Hainess, G. Nyarfas, T. Toth, V. Sarosi, Z. Baliko, L. Kovacs, F. Valikovics, J. Szegedi, S. Angyal, Z. Zilahi, A. Ferencz, S. Palinkasi, E. Walcz, J. Schlezak, M. Bisits, W. Younes; Israel: M. Moscovici, S. Oren, K. Riesenberg, F. Schlaeffer, A. Lalkin, R. Lang, M. Dan, D. Zeltser; Italy: G. Cervio, O. Filieri, A. Rossi, F. Marelli, G. Marchetti, A. Santolicandro, F. Tana, G. Meregalli, G. Losito, L. Petrozzi, D. Rizonelli, D. Sella; Norway: A. Bucher, A.B. Brandsaeter, P. Olsen, I.J. Hagen; Poland: J. Malolepszy, R. Dobek, A. Wolanczyk-Medrala, E. Liebhart, R. Suchnicka, G. Wojtas, T. Targowski, S. Gruska, M. Tazbirek, W. Pierzchala, M. Trzaska, M. Jarecki, A. Rydzewski, J. Gozdowska, M. Faber, T. Plusa, A. Kucharczyk, K Jahnz-Rozyk; Portugal: J Moita; South Africa: E. Seller, J. Crafford, M. Heystek, S. Oosthuizen, T. Fisher, Y. Botha, A. Engelbrecht, J. van Graan, L. Fourie, M. van Rooyen, S. Laloo, T. Kluÿts, W. Dannheimer, F. Ogundare, G. Ngombe, M. Siddiqui, J. Viljoen; Spain: A. Rosell, J. Morera, 
R. Pifarré, A. Torres, J. Angrill, M. Abel, C. Santana, J. Lope, J.C. Rodriguez, R. Esparza, V. Medina, J. Aspa, B. Nieto, O. Rajas, J. Fullana, C. Pellicer, M.J. Cremades, C. Vilarino, F. Iglesias, J.C. Barros, F. Del Campo, J.L. Perez, J. Frutos, M. Puyo; Sweden: M. Erntell, S.A. Hedström, B. Ljungberg, F. Killander, H. Norrgren, P. Akesson, B.O. Larsson, M. Whl, S. Jakobsson, B.O. Nillsson; Switzerland: J. Bartenstein; UK: M. Britton, P.A. Corris, S. O'Hickey, N.K. Harrison, O. Khair, M. Finnegan, D.P. Spence, T. Rogers, C. Connolly, A. Henderson.

\section{References}

1. Intercontinental Marketing Society Health Statistics. Madrid, Spain, January 2001.

2. Intercontinental Marketing Society Health Statistics. Rome, Italy, March 2001. Premature deaths, monthly mortality and monthly physician contacts: United States. Centers for Disease Control and Prevention. Morb Mortal Wkly Rpt 1997; 46: 556.

3. Pinner RW, Teutsch SM, Simonsen L, Graber JM, Clarke MJ, Berkelman RL. Trends in infectious diseases mortality in the United States. JAMA 1996; 275: 189-193.

4. Fine MJ, Smith MA, Carson CA, et al. Prognosis and outcomes of patients with community-acquired pneumonia. JAMA 1996; 275: 134-141.

5. Marston BJ, Plouffe JF, File TM Jr, et al. Incidence of community-acquired pneumonia requiring hospitalizations: results of a population-based active surveillance study in Ohio. Community based pneumonia incidence study group. Arch Intern Med 1997; 157: 1709-1718.

6. Niederman MS, McCombs JS, Unger AN, Kumar A, Popovian R. The costs of treating communityacquired pneumonia. Clin Ther 1998; 20: 820-837.

7. Fine MJ, Auble TJ, Yealy DM, et al. A prediction rule to identify low-risk patients with community-acquired pneumonia. N Engl J Med 1997; 336: 243-250.

8. Fine MJ, Hough LJ, Medsger AR, et al. The hospital admission decision for patients with communityacquired pneumonia. Arch Intern Med 1997; 157: 36- 44.

9. Fine MJ, Pratt M, Obrosky S, et al. Relation between length of hospital stay and costs of care with patients with community-acquired pneumonia. $\mathrm{Am} \mathrm{J} \mathrm{Med}$ 2000; 109: 378-385.

10. Bartlett JG, Dowell SF, Mandell LA, File TM Jr, Musher DM, Fine MJ. Practice guidelines for the management of community-acquired pneumonia in adults. Clin Inf Dis 2000; 31: 347-382.

11. Mandell LA, Marrie TJ, Grossman RF, Chow AW, Hyland RH. Canadian guidelines for the initial management of community acquired pneumonia: an evidence-based update by the Canadian Infectious Diseases Society and the Canadian Thoracic Society. Clin Inf Dis 2000; 31: 383-421.

12. European Study on Community-Acquired Pneumonia (ESOCAP) committee. Guidelines for management of adult community-acquired lower respiratory tract infections. Eur Respir J 1998; 11: 986-991.

13. Heffelfinger JD, Dowell SF, Jorgensen $\mathrm{JH}$, et al. Management of community-acquired pneumonia in the area of pneumococcal resistance. Arch Int Med 2000; 160: 1399-1408.

14. American Thoracic Society. Guidelines for the management of adults with community-acquired pneumonia. Diagnosis, assessment of severity, antimicrobial therapy, and prevention. Am J Respir Crit Care Med 2001; 163: 1730-1754.

15. Lamping DL, Schroter S, Sagnier PP, Duprat-Lomon I. Psychometric evaluation of the CAP-Sym questionnaire: A new, patient-based measure of symptoms in community acquired pneumonia. Value Health 2001; 4: 65 .

16. Ware JE, Sherbourne CD. The MOS 36-item Short Form health survey (SF-36): I Conceptual framework and item selection. Med Care 1992; 30: 473-483.

17. Ware JE. SF-36 Health Survey, Manuel Interpretation Guide. Boston, The Medical Outcomes Trust, 1993.

18. Revicki DA, Frank L. Pharmacoeconomic evaluation in the real world. Pharmacoeconomics 1999; 15: 423-434.

19. Haynes B. Can it work? Does it work? Is it worth it? The testing of health care interventions is evolving. BMJ 1999; 319: 652-653.

20. Simon G, Wagner E, Vonkorff M. Cost-effectiveness comparisons using "real-world" randomized trials: the case of new anti-depressant drugs. J Clin Epidemiol 1995; 48: 363-373.

21. Samsa GP, Reutter RA, Parmigiani G, et al. Performing cost-effectiveness analysis by integrating randomized trial data with a comprehensive decision model: application to treatment of acute ischemic stroke. J Clin Epidemiol 1999; 52: 259-271.

22. The West of Scotland Coronary Prevention Study Group. Computerized record linkage: compared with traditional patient follow-up methods in clinical trials and illustrated in a prospective epidemiological study. $J$ Clin Epidemiol 1995; 48: 1441-1452.

23. Roland $\mathrm{M}$, Torgeson DJ. What are pragmatic trials? BMJ 1998; 316: 285.

24. Schwartz D, Lellouch J. Explanatory and pragmatic attitudes in therapeutic trials. J Chron Dis 1967; 20: 637-648.

25. Fayers PM, Hand DJ. Generalisation from phase III clinical trials: survival, quality of life and health economics. Lancet 1997; 350: 1025-1027.

26. Bailey KR. Generalizing the results of randomized clinical trials. Control Clin Trials 1994; 15: 15-23.

27. Rubins HB. From clinical trials to clinical practice: generalizing from participant to patient. Control Clin Trials 1994; 15: 7-10.

28. Petitpretz P, Arvis P, Miroslav M, Moita J, Urueta J and the CAP 5 Moxifloxacin Study Group. Oral moxifloxacin $v s$ high-dosage amoxicillin in the treatment of mild-to-moderate, community-acquired, suspected pneumococcal pneumonia in adults. Chest 2001; 119: 185-195.

29. Aubier M, Verster R, Regamey C, Geslin P, Vercken JB. Once-daily sparfloxacin versus high-dosage amoxicillin in the treatment of community-acquired, suspected pneumococcal pneumonia in adults. Clin Infect Dis 1998; 26: 1312-1320.

30. O'Doherty B, Dutchman DA, Pettit R, Maroli A. Randomized, double-blind, comparative study of grepafloxacin and amoxycillin in the treatment of patients with community-acquired pneumonia. J Antimicrob Chemother 1997; 40: Suppl. A, 73-81.

31. Tremolieres F, de Kock F, Pluck N, Daniel R. Trovafloxacin versus high-dose amoxicillin $(1 \mathrm{~g}$ three 
times daily) in the treatment of community-acquired bacterial pneumonia. Eur J Clin Microbiol Infect Dis 1998; 17: 447-453.

32. File TM Jr, Segreti J, Dunbar L, et al. A multicenter, randomized study comparing the efficacy and safety of intravenous and/or oral levofloxacin versus ceftriaxone and/or cefuroxime axetil in the treatment of adults with community-acquired pneumonia. Antimicrob Agents Chemother 1997; 41: 1965-1972.

33. Norby SR, Petermann W, Wilcox PA, Vetter N, Salewski E. A comparative study of levofloxacin and ceftriaxone in the treatment of hospitalized patients with pneumonia. Scand J Infect Dis 1998; 30: 397-404.

34. Adams M, Sullivan J, Henry D, et al. Comparison of grepafloxacin with cefaclor in the treatment of community-acquired pneumonia. In: Program and Abstracts of the 37th International Conference on Antimicrobial Agents and Chemotherapy. Toronto, American Society for Microbiology, 1997; p. 377.

35. Niederman M, Traub S, Ellison WT, Hopkins DW and the TROVAN Pneumonia Study Group. A double-blind, randomized, multicenter, global study in trovafloxacin with ceftriaxone plus erythromycin [abstract LM-72]. In: Program and Abstracts of the 37th International Conference on Antimicrobial Agents and Chemotherapy. Toronto, American Society for Microbiology, 1997; pp. 377-378.

36. Fogarty C, Grossman C, Williams J, Haverstock D, Church D. Efficacy and safety of moxifloxacin vs clarithromycin for community-acquired pneumonia. Infect Med 1999; 16: 748-763.

37. Moola S, Hagberg L, Churchyard A, Sedani S, Staley $\mathrm{H}$ and the RAXAR CAP Study Group. Comparison of grepafloxacin with clarithromycin in the treatment of community-acquired pneumonia (CAP). In: Program and Abstracts of the 38th International Conference on Antimicrobial Agents and Chemotherapy. San Diego, American Society for Microbiology, 1998; p. 582.

38. Patel T, Desai R, Duff J, Johnson ME, Breisch SA, Maroli AN. Comparison of grepafloxacin (GFX) with clarithromycin (CLA) in the treatment of community-acquired pneumonia (CAP). In: Program and Abstracts of the 37th International Conference on Antimicrobial Agents and Chemotherapy. Toronto, American Society for Microbiology, 1997; p. 378.

39. Sullivan J, Gezon J, Williams-Hopkins D and the TROVAN Pneumonia Study Group. A doubleblind, randomized multicenter study in ambulatory community-acquired pneumonia (CAP) comparing trovafloxacin with clarithromycin. In: Program and Abstracts of the 37th International Conference on Antimicrobial Agents and Chemotherapy. Toronto, American Society for Microbiology, 1997; p. 378.

40. Ramirez J, Unowsky J, Talbot GH, Zhang H, Townsend L. Sparfloxacin versus clarithromycin in the treatment of community-acquired pneumonia. Clin Ther 1999; 21: 103-117.

41. Ortqvist A, Valtonen M, Cars O, Wahl M, Saikku P, Jean C. Oral empiric treatment of communityacquired pneumonia: a multicenter, double-blind, randomized study comparing sparfloxacin with roxithromycin. Chest 1996; 110: 1499-1506.

42. Iannini PB, Kubin R, Reiter C, Tillotson G. Reassuring safety profile of moxifloxacin. Clin Inf Dis 2001; 32: 1112-1114.

43. Tillotson GS, Rybak MJ. Milestone in quinolone safety profile. Pharmacotherapy 2001; 21: 358-360. 